IOS Press

\title{
Obituary
}

\section{Jerry Labadie, a life dedicated to vaccine safety}

Jerry Labadie (born in 1957) graduated from Leiden University Medical School as a medical doctor. After a fellowship in pediatrics he worked from 1993 at the National Institute for Public Health and the Environment (RIVM) in the Netherlands, where he was involved in registration and analysis of adverse events of vaccines for the Netherlands National Immunization Programme, and many medical issues related to vaccine production and clinical development. In 2000 he moved to the Netherlands Pharmacovigilance Centre Lareb where he worked as assessor of ADR-reports and as regional officer in Amsterdam, with special focus on vaccines. In 2009 he joined the Uppsala Monitoring Centre in Sweden as a vaccine specialist. This enabled his possibilities to improve the quality of ADR reporting for vaccines worldwide, especially in low income countries. Jerry combined his clinical expertise and his experiences in pharmacovigilance with the diplomatic skills needed to bring vaccine safety further in this difficult field. He participated in several projects of the Brighton Collaboration and was a board member of The International Journal of Risk \& Safety in Medicine.

Jerry was very personable and had a good sense of humor. He was regarded as a kind and easy going but thoughtful man, concerned for the needs of others. He had the ability to explain complex issues in an easy and simple manner. Jerry was an excellent teacher, combining his vast knowledge with compassion, setting a fine example to his junior colleagues.

Alternately, he worked in the Netherlands and Sweden, but his work took him to all corners of the world. He enjoyed traveling, was always working hard, but also considered it important to keep a good balance between work and his private life. He was devoted to his wife and proud of his four children.

On August 1st, Jerry died due to a car accident in Sweden. He will be greatly missed by his wife Inger and his children Shari, Esmay, Lionel and Audrey and all of us who had the luck to have known his knowledge, commitment and friendship.

Eugene van Puijenbroek Netherlands Pharmacovigilance Centre Lareb

Goudsbloemvallei 7

$5237 \mathrm{MH}$ 's-Hertogenbosch

The Netherlands

E-mail: E.vanPuijenbroek@lareb.nl 